\title{
Characterization of the Soybean GmIREG Family Genes and the Function of GmIREG3 in Conferring Tolerance to Aluminum Stress
}

\author{
Zhandong Cai ${ }^{1,2,3}$, Peiqi Xian ${ }^{1,2,3}$, Rongbin Lin ${ }^{1,2,3}$, Yanbo Cheng ${ }^{1,2,3}$, Tengxiang Lian ${ }^{1,2,3}$, \\ Qibin Ma ${ }^{1,2,3}$ and Hai Nian 1,2,3,* \\ 1 The State Key Laboratory for Conservation and Utilization of Subtropical Agro-Bioresources, South China \\ Agricultural University, Guangzhou 510642, China; zdcai@stu.scau.edu.cn (Z.C.); \\ pqxian@stu.scau.edu.cn (P.X.); linrbl@163.com (R.L.); ybcheng@scau.edu.cn (Y.C.); liantx@scau.edu.cn (T.L.); \\ maqibin@scau.edu.cn (Q.M.) \\ 2 The Key Laboratory of Plant Molecular Breeding of Guangdong Province, College of Agriculture, \\ South China Agricultural University, Guangzhou 510642, China \\ 3 The Guangdong Subcenter of the National Center for Soybean Improvement, College of Agriculture, \\ South China Agricultural University, Guangzhou 510642, China \\ * Correspondence: hnian@scau.edu.cn; Tel.: +8602085288024
}

Received: 21 December 2019; Accepted: 11 January 2020; Published: 13 January 2020

\begin{abstract}
The IREG (IRON REGULATED/ferroportin) family of genes plays vital roles in regulating the homeostasis of iron and conferring metal stress. This study aims to identify soybean IREG family genes and characterize the function of GmIREG3 in conferring tolerance to aluminum stress. Bioinformatics and expression analyses were conducted to identify six soybean IREG family genes. One GmIREG, whose expression was significantly enhanced by aluminum stress, GmIREG3, was studied in more detail to determine its possible role in conferring tolerance to such stress. In total, six potential IREG-encoding genes with the domain of Ferroportin1 (PF06963) were characterized in the soybean genome. Analysis of the GmIREG3 root tissue expression patterns, subcellular localizations, and root relative elongation and aluminum content of transgenic Arabidopsis overexpressing GmIREG3 demonstrated that GmIREG3 is a tonoplast localization protein that increases transgenic Arabidopsis aluminum resistance but does not alter tolerance to $\mathrm{Co}$ and Ni. The systematic analysis of the GmIREG gene family reported herein provides valuable information for further studies on the biological roles of GmIREGs in conferring tolerance to metal stress. GmIREG3 contributes to aluminum resistance and plays a role similar to that of FeIREG3. The functions of other GmIREG genes need to be further clarified in terms of whether they confer tolerance to metal stress or other biological functions.
\end{abstract}

Keywords: expression pattern; metal stress; transporter; tonoplast; detoxification

\section{Introduction}

Plants absorb mineral elements from soil and transport them to various organs and tissues for normal growth and development, which requires different types of transporters, including the natural resistance-associated macrophage protein family of transporters, the zinc/iron-regulated transporter-like protein family, heavy metal ATPase transporters, multidrug and toxic compound extrusion protein transporters, the ATP-binding cassette family of transporters, and others [1-4]. However, because of the low affinity of certain transporters, toxic metal ions can accumulate in the roots while transporting essential mineral elements for normal growth and development under deficiency conditions [5]. Fortunately, plants have developed elaborate regulatory mechanisms to perceive the metal stress signals and adjust metal detox pathways by modulating the expression of genes, such as 
$\mathrm{NADH}$ dehydrogenase subunit 1 [6], plasma membrane $\mathrm{H}^{+}$-ATPase [7], half-size ABC transporters [8,9], and IRON REGULATED/ferroportin (IREG) transporters [2,5,10,11].

The IREG family, with its highly conserved domain, exists in a wide range of bacteria, animals, and plants [5]. Some members of this family in plants have been functionally characterized, especially in model plants such as Arabidopsis (Arabidopsis thaliana). There are only three members of the IREG transporter protein family in Arabidopsis. AtIREG1 is localized in the plasma membrane and is expressed in the root stele, which is essential for cobalt tolerance and iron homeostasis [10]. Unlike AtIREG1, AtIREG2 is localized in the vacuolar membrane of root cells and functions as a transporter for cobalt and nickel into the vacuole [5]. AtIREG3 (also known as MAR1) is a plastid transporter that might play roles in the regulation of cellular iron homeostasis, and may be involved in controlling the opportunistic entry of multiple antibiotics into the chloroplast [12,13]. In Psychotria gabriellae, PgIREG1 behaves as a functional orthologue of the AtIREG2 at the cellular level, and is also localized in the vacuolar membrane and involved in Ni tolerance [2]. Recently, FeIREG1 from Fagopyrum esculentum Moench was shown to be an Al-specific IREG transporter involved in tolerance to $\mathrm{Al}$ toxicity but not to other metals [11]. These findings indicate that the functions of IREGs are different among plant species.

Aluminum is the most widely distributed metal element on earth. Because of its excellent properties, it is among the most universal engineering and construction materials in industry. Unlike essential transition metals, $\mathrm{Al}$ is a nonessential element for plants, and micromolar concentrations of $\mathrm{Al}$ can harm the root growth of plants [8]. With the increasing acidification of soils and waters, $\mathrm{Al}$ toxicity accompanied by manganese toxicity or phosphorus deficiency has become a major limitation to crop growth in acidic soils [14,15]. Two main types of $\mathrm{Al}$ resistance mechanisms have been established in plant species during long-term evolution, i.e., exclusion mechanisms and internal tolerance mechanisms [16-18]. Multidrug and toxic compound extrusion (MATE) transporters and aluminum-activated malate transporter (ALMT) are crucial for Al-induced organic acid efflux, which can detoxify $\mathrm{Al}$ internally and externally $[15,19,20]$. Vacuoles play an important role in internal tolerance mechanisms due to their function of storing $\mathrm{Al}$ in plant cells. Proteins localized on the vacuole membrane such as AtALS1, OsALS1, and FeIREG1 play an active role in resistance to Al toxicity $[8,9,11]$.

Soybean (Glycine max L.) is one of the most important sources of protein, oil, and micronutrients, and is particularly sensitive to Al toxicity. Although a few Al-tolerant genes involved in exclusion mechanisms and internal tolerance mechanisms have been functionally characterized, gene resources involved in Al tolerance in soybean are not sufficient compared with those in rice and wheat. Furthermore, few data are available concerning the IREG gene family in soybean to date. In the present study, a bioinformatics analysis was conducted to identify six soybean IREG genes. GmIREG3, whose expression was significantly enhanced by aluminum stress, was studied in transgenic Arabidopsis to determine its possible role in conferring tolerance to aluminum stress.

\section{Results}

\subsection{Bioinformatics Analysis of Six IREG Genes in Soybean}

Six potentially encoding IREG proteins were blasted from the soybean genome in the Phytozome database using the protein domain of Ferroportin1 (PF06963) and termed GmIREG1 to GmIREG6. Chromosome mapping showed that the six GmIREGs are distributed on four chromosomes. Chromosomes 1 and 3 each contained two GmIREGs, while chromosomes 10 and 20 each contained one GmIREG (Table 1 and Figure S1). The CDS regions of six soybean IREG genes ranged from 528 (GmIREG4) to 1764 (GmIREG5) bp in length, encoding proteins with lengths of 175 (GmIREG4) to 587 (GmIREG5) aa. The molecular weights (MWs) ranged from $19.06 \mathrm{kDa}$ to $63.19 \mathrm{kDa}$, and PI values ranged from 6.16-9.07. 
Table 1. Summary of IREG family genes in soybean.

\begin{tabular}{cccccccc}
\hline $\begin{array}{c}\text { Gene } \\
\text { Name }\end{array}$ & Chromosome & Gene Locus & $\begin{array}{c}\text { Length of } \\
\text { CDS (bp) }\end{array}$ & $\begin{array}{c}\text { No. of Amino } \\
\text { Acids (aa) }\end{array}$ & $\begin{array}{c}\text { MW } \\
\text { (kD) }\end{array}$ & PI & $\begin{array}{c}\text { Protein Domain } \\
\text { Family }\end{array}$ \\
\hline GmIREG1 & 1 & Glyma.01G128300 & 1506 & 501 & 56.21 & 7.04 & $\begin{array}{c}\text { Ferroportin1 } \\
\text { (PF06963) }\end{array}$ \\
\hline GmIREG2 & 1 & Glyma.01G128400 & 1023 & 340 & 38.22 & 8.64 & $\begin{array}{c}\text { Ferroportin1 } \\
\text { (PF06963) }\end{array}$ \\
\hline GmIREG3 & 3 & Glyma.03G042400 & 1509 & 502 & 56.14 & 7.58 & $\begin{array}{c}\text { Ferroportin1 } \\
\text { (PF06963) }\end{array}$ \\
\hline GmIREG4 & 3 & Glyma.03G042500 & 528 & 175 & 19.06 & 9.07 & $\begin{array}{c}\text { Ferroportin1 } \\
\text { (PF06963) }\end{array}$ \\
\hline GmIREG5 & 10 & Glyma.10G146600 & 1764 & 587 & 63.19 & 7.60 & $\begin{array}{c}\text { Ferroportin1 } \\
\text { (PF06963) }\end{array}$ \\
\hline GmIREG6 & 20 & Glyma.20G096400 & 1251 & 416 & 45.19 & 6.16 & $\begin{array}{c}\text { Ferroportin1 } \\
\text { (PF06963) }\end{array}$ \\
\hline
\end{tabular}

The multiple sequence alignment and phylogenetic investigation were conducted with the inclusion of IREGs from Arabidopsis thaliana, rice, and two published IREGs (PgIREG1 and FeIREG1). As shown in Figure 1, fifteen IREGs, including six GmIREGs, were classified into three groups. Group I was composed of nine IREG proteins including four GmIREGs (GmIREG1, GmIREG2, GmIREG3, and GmIREG4), and group II was composed of six IREG proteins including GmIREG5 and GmIREG6. Phylogenetic analysis indicated that GmIREG1, GmIREG2, GmIREG3, and GmIREG4 cluster closely with three published IREGs having the function of transporting metal ions: AtIREG2 from Arabidopsis thaliana, PgIREG1 from Psychotria gabriellae, and FeIREG1 from Fagopyrum esculentum Moench.

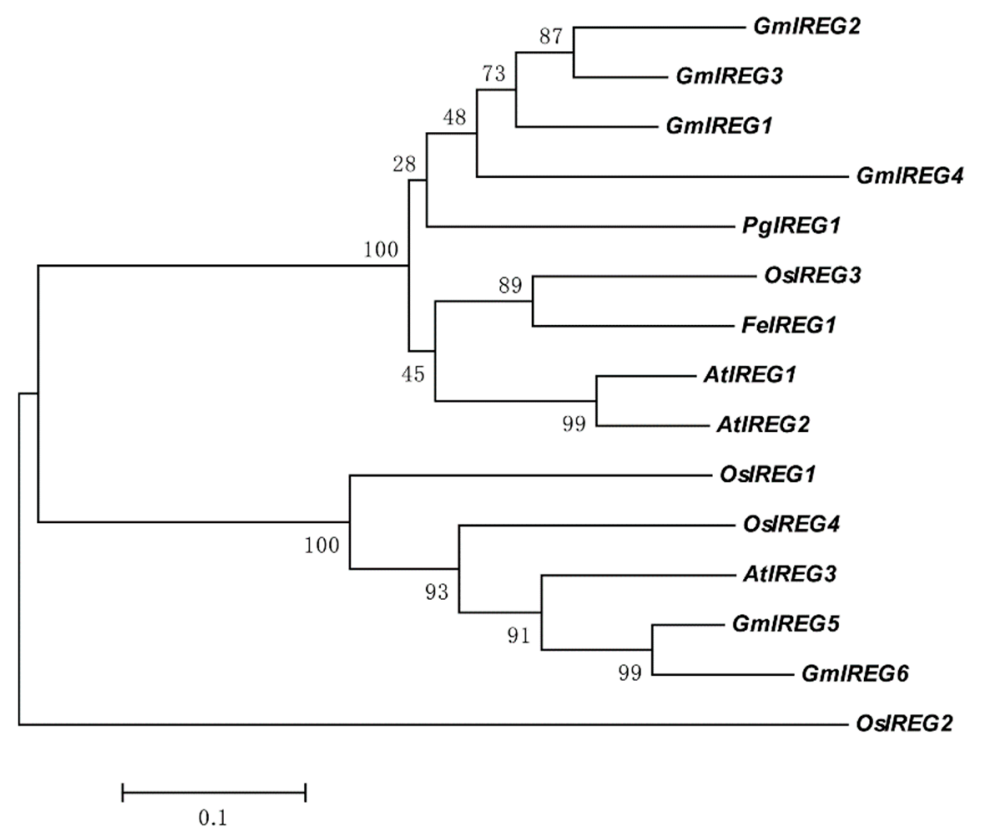

Figure 1. Phylogenetic analysis of the GmIREGs and published IREG proteins. The phylogenetic tree was constructed using the neighbor-joining method with 1000 bootstrap replicates by MEGA 7.0 software. The accession numbers for soybean IREG genes can be found in Table 1, and the other accession numbers are as follows: AtIREG1 (At2g38460), AtIREG2 (At5g03570), AtIREG3 (At5g26820), OsIREG1 (LOC_Os05g04120), OsIREG2 (LOC_Os06g14170), OsIREG3 (LOC_Os06g36450), OsIREG4 (LOC_Os12g37530), and PgIREG1 (CCM80483.1). The amino acid sequence of FeIREG1 can be found in [11]. 


\subsection{Expression Patterns of GmIREG Genes}

Based on the expression data in Phytozome, a heat map of the tissue expressions was analyzed (Figure 2A). All GmIREGs were detected in each tissue except GmIREG2. Expression was high for GmIREG5 in all tissues, and was highest for GmIREG5 in flowers. Relatively high expression was also observed for GmIREG1 in nodules and GmIREG3 in root. Moreover, we tested whether the soybean GmIREGs expression were induced by metals using qRT-PCR (Figure 2B). Exposure of soybean roots to $\mathrm{Al}$ only induced the expression of GIIREG3. With exposure to $\mathrm{Cd}$, the expression of GmIREG4 was significantly downregulated, but the GMIREG5 was significantly upregulated. GmIREG5 and GmIREG6 were upregulated by Ni. However, the expression levels of six soybean GmIREGs were not altered by $\mathrm{Co}$ and Fe.
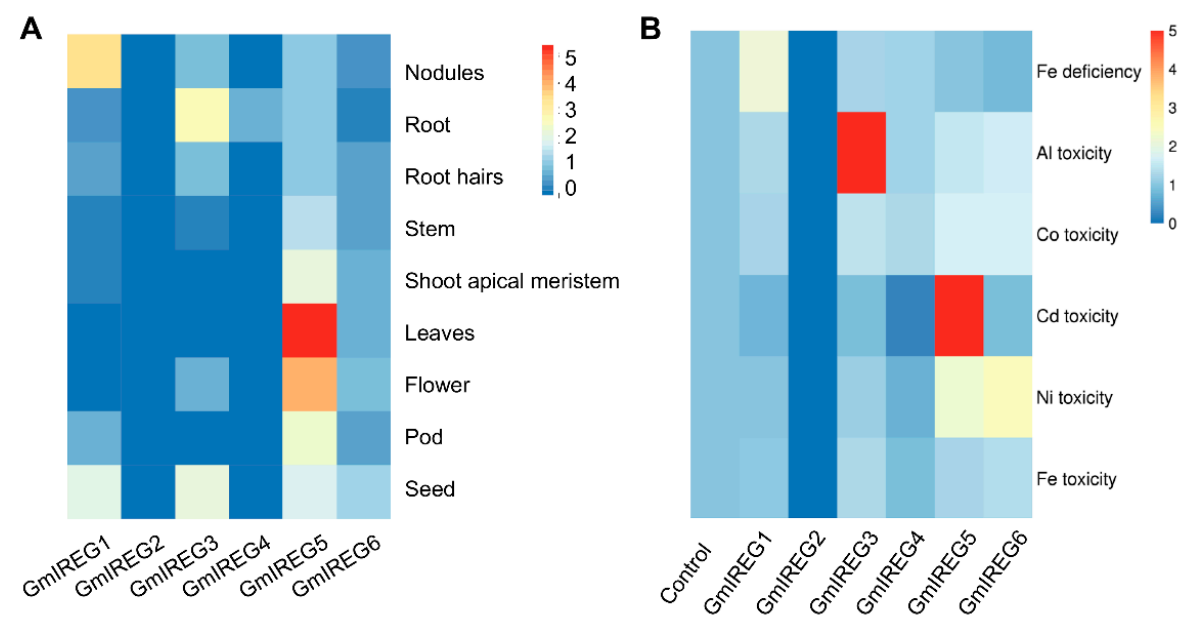

Figure 2. Tissue-specific expression and metal-induced expression patterns of six soybean IREG genes. (A) Heat map analysis shows the different tissue specific expression pattern of GmIREGs using the PKFM data of phytozome v12 database. (B) Expression of GmIREGs in response to Fe deficiency, Al toxicity, Co toxicity, Cd toxicity, Ni toxicity, and Fe toxicity. For Fe deficiency, uniform seedlings were exposed to normal conditions (half-strength nutrient solution, $\mathrm{pH}$ 5.6) or low-iron conditions (half-strength nutrient solution without Fe-Na-EDTA, pH 5.6) for 14 days. For other toxicity treatments, the uniform seedlings were treated with excess Fe (1000 $\mu \mathrm{M}$ Fe-EDTA), $\mathrm{Ni}\left(30 \mu \mathrm{M} \mathrm{NiCl}_{2} \cdot 6 \mathrm{H}_{2} \mathrm{O}\right), \mathrm{Cd}$ $\left(30 \mu \mathrm{M} \mathrm{CdCl}_{2}\right), \mathrm{Co}\left(30 \mu \mathrm{M} \mathrm{CoCl}_{2}\right)$, and $\mathrm{Al}\left(30 \mu \mathrm{M} \mathrm{AlCl} \mathrm{Cl}_{3} \cdot 6 \mathrm{H}_{2} \mathrm{O}\right)$ treatments for $12 \mathrm{~h}$. The roots were separately harvested for qRT-PCR analysis. The heat map displays $2^{\Delta \Delta C t}$ values to show relative expression of metal treated samples vs. controls.

\subsection{Cloning and Characterization of GmIREG3}

On the basis of sequence information of GmIREG3 from the Phytozome database, we obtained the full-length GmIREG3 cDNA (GenBank accession number: MN635747) and approximately 2-Kb promoter sequence (GenBank accession number: MN781668) from HX3 (Al-tolerant genotype). In agreement with the prediction of the Phytozome database, the GmIREG3 coding region was $1509 \mathrm{bp}$ in length and encoded a protein of 502 amino acids. A BLAST search of orthologues in Arabidopsis showed that GmIREG3 shared 71.5\%, 73.5\%, and 75.7\% similarity with AtIREG1, AtIREG2, and FeIREG1, respectively (Figure 3A). To further reveal the divergence of the GmIREG3 protein during evolution, a BLAST analysis in NCBI with the protein sequence of GmIREG3 was performed; we found that GmIREG3 and genes of leguminous plants such as Arachis hypogaea and Medicago truncatula are in the same clade (Figure S2). Furthermore, the orthologues are present in both monocots and dicots, and the proteins may be classified into two distinct clades, which suggested the evolution of GmIREG3 and orthologues before the divergence of monocots and dicots. To identify the subcellular location of GmIREG3, its coding region was fused upstream of the GFP gene and expressed under the 
CaMV35S promoter in leaves of Nicotiana benthamiana. Confocal images demonstrated that GmIREG3 was colocated with the tonoplast marker to the tonoplast (Figure 3B).

A

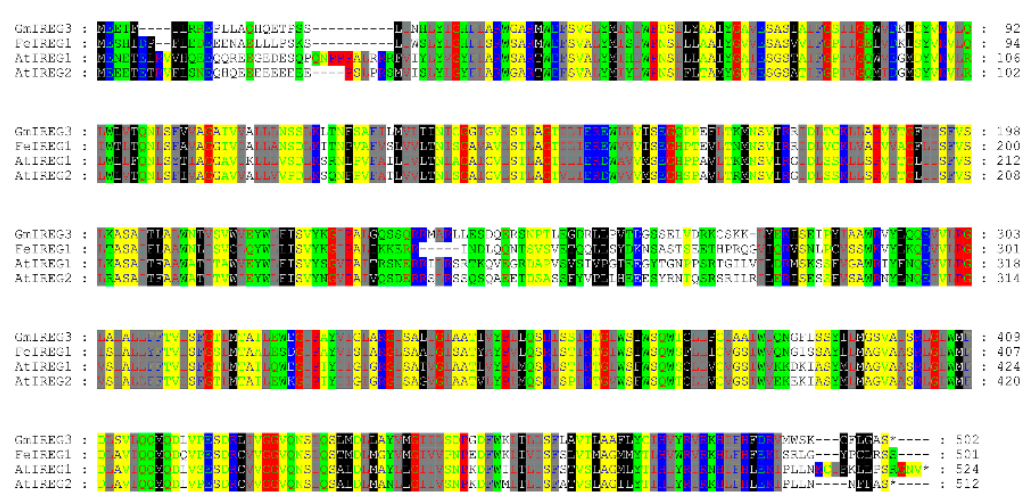

B
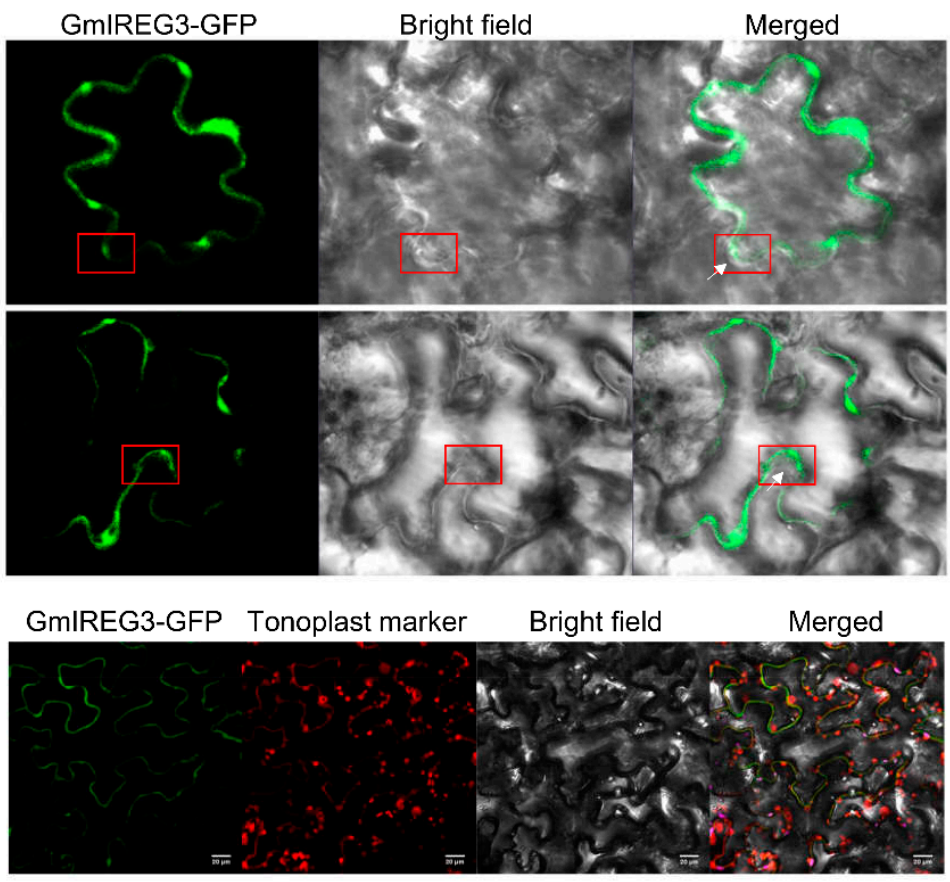

Figure 3. Alignment of amino acid sequence and subcellular localization of GmIREG3. (A) Amino acid sequence alignment of IREG proteins from soybean (GmIREG3), buckwheat (FeIREG1) and Arabidopsis (AtIREG1 and AtIREG2). (B) Subcellular localization of a C-terminal GmIREG3-GFP fusion protein in Nicotiana benthamiana and the fusion protein was driven by $35 \mathrm{~S}$ promoter. At $3 \mathrm{~d}$ after infiltration, the fluorescence signals were visualized by confocal microscopy. GmIREG3-GFP was colocated with the tonoplast marker to the tonoplast. Red rectangles indicate the tonoplast separated from the plasma membrane and white arrows indicate the plasma membrane.

The 1958-bp promoter of GmIREG3 was cloned and sequenced. Based on the PlantCARE analysis, the promoter of GmIREG3 contained a few cis-elements involved in plant hormone signaling, including elements associated with abscisic acid-responsive element (ABRE), salicylic acid-responsive element (TCA), and the gibberellin-responsive element (P-box), which play significant roles in regulating the growth of plant and stress responses. Some cis-elements associated with light responses were also identified in the GmIREG3 promoter such as ACE, Box-4, and G-box. Additionally, both basal elements, i.e., CAAT-box and TATA-box, and stress-related cis-acting elements W-box, MBS, and LTR are contained in the in the GmIREG3 promoter (Table 2). 
Table 2. The cis-acting elements identified in GmIREG3 promoter.

\begin{tabular}{|c|c|c|c|c|}
\hline Site name & Species & Position & Sequence & Function \\
\hline ABRE & $\begin{array}{l}\text { Arabidopsis } \\
\text { thaliana }\end{array}$ & 1643 & ACGTG & $\begin{array}{l}\text { cis-acting element involved in the } \\
\text { abscisic acid responsiveness }\end{array}$ \\
\hline $\mathrm{ACE}$ & $\begin{array}{l}\text { Petroselinum } \\
\text { crispum }\end{array}$ & -809 & GACACGTATG & $\begin{array}{l}\text { cis-acting element involved in } \\
\text { light responsiveness }\end{array}$ \\
\hline Box 4 & $\begin{array}{l}\text { Petroselinum } \\
\text { crispum }\end{array}$ & $\begin{array}{c}-1019 /-1918 / \\
-1477 /-1463 / \\
-1515\end{array}$ & ATTAAT & $\begin{array}{l}\text { part of a conserved DNA module } \\
\text { involved in light responsiveness }\end{array}$ \\
\hline G-box & Zea mays & -1642 & CACGTC & $\begin{array}{l}\text { cis-acting regulatory element } \\
\text { involved in light responsiveness }\end{array}$ \\
\hline LTR & $\begin{array}{l}\text { Hordeum } \\
\text { vulgare }\end{array}$ & -1794 & CCGAAA & $\begin{array}{l}\text { cis-acting element involved in } \\
\text { low-temperature responsiveness }\end{array}$ \\
\hline MBS & $\begin{array}{l}\text { Arabidopsis } \\
\text { thaliana }\end{array}$ & +290 & CAACTG & $\begin{array}{l}\text { MYB binding site involved in } \\
\text { drought-inducibility }\end{array}$ \\
\hline P-box & Oryza sativa & -1927 & CCTTTTG & gibberellin-responsive element \\
\hline TCA & $\begin{array}{l}\text { Nicotiana } \\
\text { tabacum }\end{array}$ & -833 & ССАТСТTTTT & $\begin{array}{l}\text { cis-acting element involved in } \\
\text { salicylic acid responsiveness }\end{array}$ \\
\hline W box & $\begin{array}{l}\text { Arabidopsis } \\
\text { thaliana }\end{array}$ & -1924 & TTGACC & $\begin{array}{l}\text { cis-acting element involved in } \\
\text { stress responsiveness }\end{array}$ \\
\hline
\end{tabular}

\subsection{Root GmIREG3 Expression Levels Are Increased by Al}

To further examine the expression patterns of GmIREG3 following Al stress, three-day-old root tips of soybean were exposed to different concentrations and durations of Al. Spatial expression analysis showed that the expression levels of GmIREG3 were induced in 0-5 cm root segments by $30 \mu \mathrm{M} \mathrm{Al}$ (Figure 4A). However, the expression induction was much greater in the root tips than in other root segments (Figure 4A). In a dose-response experiment, as shown in Figure 4B, the expression of GmIREG3 increased with increasing Al concentration. Furthermore, the Al-induced expression of GmIREG3 was found to increase rapidly within $8 \mathrm{~h}$ of exposure to $30 \mu \mathrm{M} \mathrm{Al}$ and decrease after $8 \mathrm{~h}$ of exposure (Figure 4C).
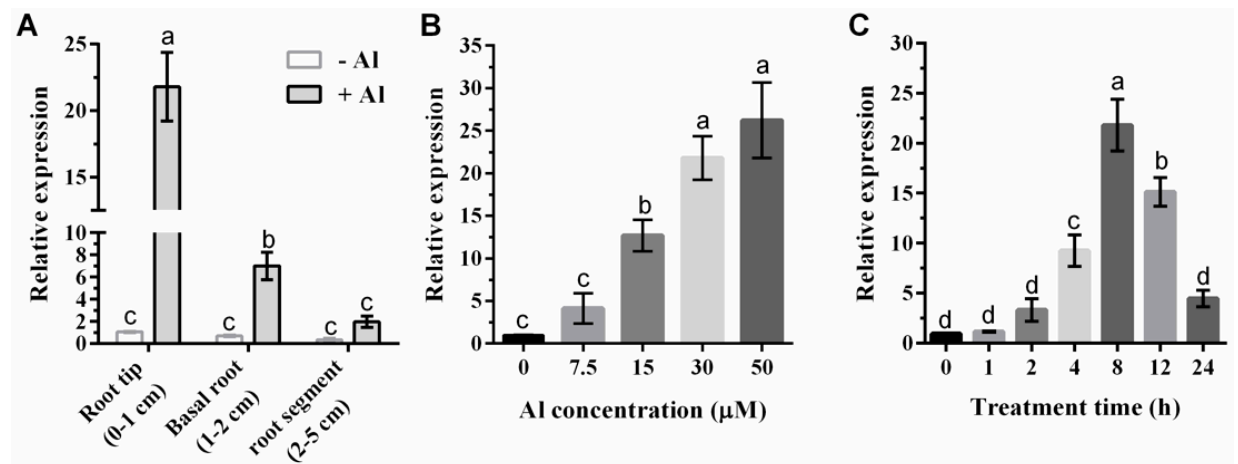

Figure 4. Soybean GmIREG3 expression analysis. (A) Tissue-specific expression of GmIREG3 in response to $\mathrm{Al}$ stress. Samples for spatial expression were taken from different root segments $(0-1,1-2$ and $2-5 \mathrm{~cm}$ from the apex) of seedlings with or without $30 \mu \mathrm{M} \mathrm{Al}$ treatment. (B) Dose-dependent GmIREG3 expression in soybean root tips $(0-1 \mathrm{~cm})$. The roots were exposed to different $\mathrm{Al}$ concentrations $(0,7.5$, 15,30 , and $50 \mu \mathrm{M}$ ) for $8 \mathrm{~h}$. (C) For the time-course experiment, seedlings were exposed to $30 \mu \mathrm{M} \mathrm{AlCl}$ for $0,1,2,4,8,12$, or $24 \mathrm{~h}$. The samples were separately harvested for qRT-PCR analysis. Values are expressed as the means $\pm \mathrm{SD}(n=3)$. Different letters indicate a statistically significant difference, using one-way ANOVA and Duncan's test $(p<0.05)$. 


\subsection{Overexpression of GMIREG3 in Transgenic Arabidopsis Thaliana Confers Al Tolerance}

To evaluate the role of GmIREG3 in the Al stress response, a 35::GmIREG3 construct was introduced into Arabidopsis thaliana by the Agrobacterium tumefaciens-mediated floral-dip method [21,22]. Two independent homozygous T4 transgenic lines with higher expression (OX-4 and OX-7) were selected for phenotypic and physiological analysis (Figure S3). To test the Al tolerance wild-type (WT) and transgenic lines, the uniform seedlings (approximately $1.0 \mathrm{~cm}$ ) of these lines were transferred to $\mathrm{CaCl}_{2}$ agar plates with $0,25,50$, or $100 \mu \mathrm{M} \mathrm{AlCl}_{3}$. As shown in Figure 5, we did not observe any difference in root growth between WT and transgenic lines in the absence of Al. However, in the presence of $25 \mu \mathrm{M} \mathrm{Al}$, the root elongation of WT was inhibited by $12 \%$ after three days, but transgenic lines were not significantly influenced. With the increase of Al concentration, the root elongation of both WT and transgenic lines was inhibited. At $100 \mu \mathrm{M} \mathrm{Al}$, the root elongation of WT was inhibited by $58 \%$ and that of the transgenic lines was inhibited by 19\% (Figure 5B). The concentration of $\mathrm{Al}$ in the fresh weight of the roots was also observed. In the case of equal biomass, overexpression of GmIREG3 in Arabidopsis thaliana slightly decreased the $\mathrm{Al}$ accumulation in roots compared with the WT at relatively high concentrations of $\mathrm{Al}(100 \mu \mathrm{M} \mathrm{Al})$, but no difference was observed at low concentrations of $\mathrm{Al}$ (Figure 5C). No large difference was observed in the accumulation of $\mathrm{K}, \mathrm{Mg}$, and $\mathrm{Fe}$ in the roots, but there was a significant difference in Ca content between the WT and GmIREG3-overexpressing lines (Figure 6).

A

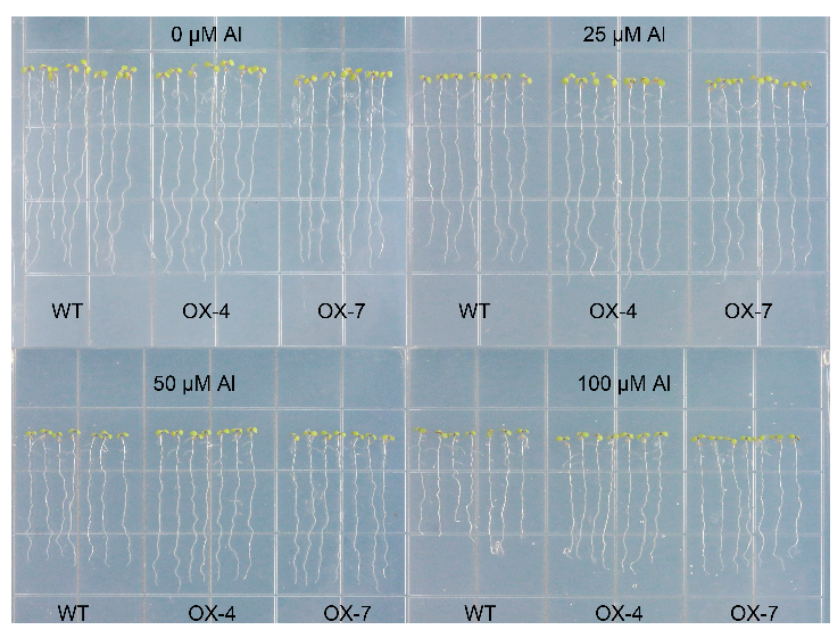

$\mathrm{B}$

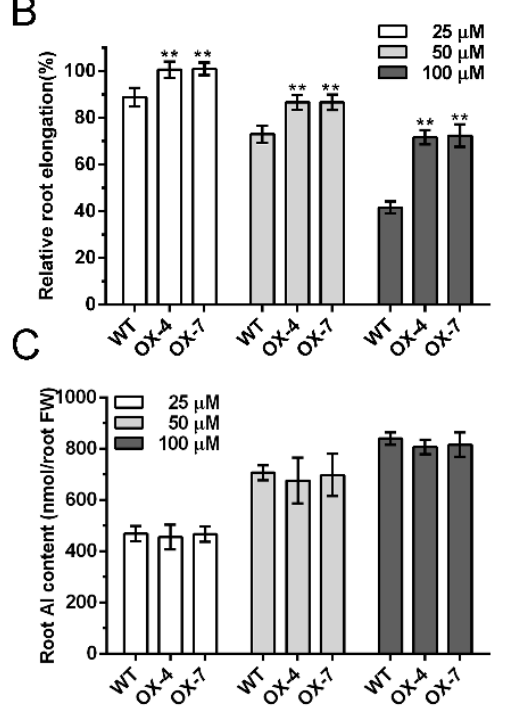

Figure 5. Overexpression of GmIREG3 enhances Al tolerance in Arabidopsis. (A) Evaluation of $\mathrm{Al}$ tolerance in GmIREG3 overexpression lines. After germination in MS medium, five-day-old seedlings were transferred to solid agar medium supplied with $1 \mathrm{mM} \mathrm{CaCl} 2$ and $1 \%$ sucrose containing different concentrations of $\mathrm{AlCl}_{3}(0,25,50$ or $100 \mu \mathrm{M}$; pH 4.5) for $3 \mathrm{~d}$. The photograph was taken for different treatments at the end of the experiment. The relative root elongation $(n=14)(\mathbf{B})$ and root $\mathrm{Al}$ concentration were measured $(n=3)(C)$. All data are presented as means \pm SD. Significant differences according to the one-way analysis of variance are denoted as follows: ${ }^{* *} p<0.01$. 

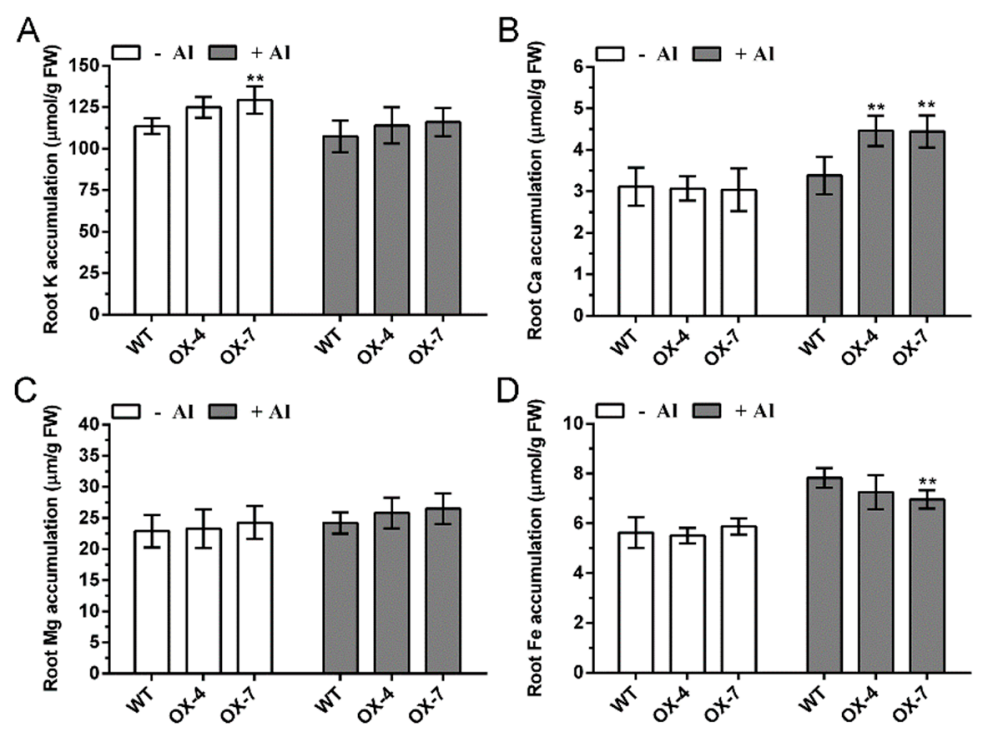

Figure 6. Concentration of other metals in transgenic Arabidopsis overexpressing GmIREG3. Arabidopsis plants were exposed to 0 or $10 \mu \mathrm{M} A l$ solution for $2 \mathrm{~d}$ and then subjected to determination of $\mathrm{K}(\mathrm{A}), \mathrm{Ca}$ (B), $\mathrm{Mg}(\mathbf{C})$ and $\mathrm{Fe}(\mathbf{D})$. Data are means $\pm \mathrm{SD}(n=3)$. Significant differences according to the one-way analysis of variance are denoted as follows: ${ }^{* *} p<0.01$.

\section{Discussion}

IREG proteins are widespread in all organisms including bacteria, animals, and plants. The IREG gene family has been reported in Arabidopsis thaliana, Psychotria gabriellae, and Fagopyrum esculentum Moench, but to the best of our knowledge, the information on this family is limited for soybean. The present study aimed to perform the genome-wide analysis of soybean IREG genes and investigate the function of GmIREG3 gene response to Al toxicity. Our results show that six IREG genes in the soybean genome harbored the typical Ferroportin1 (PF06963) domain (Table 1 and Figure S1). Phylogenetic analysis clustered these six IREG proteins into two distinct subfamilies (Figure 1). The five IREG genes were constitutively expressed in soybean plants, while the expression data of GmIREG2 could not be detected in all our samples (Figure 2). Although IREG genes function in both iron absorption in the intestine and iron recycling in macrophages in mammals, several previous studies revealed that IREG genes play different roles in plants [11,23]. In soybean, GmIREG1 was significantly affected by Fe deficiency in roots and shoots (Figure 2B), indicating that GmIREG1 might also be involved in Fe deficiency. Recent studies have revealed important roles for IREG genes in regulating metal homeostasis in plant cells, especially $\mathrm{Ni}, \mathrm{Co}$, and $\mathrm{Al}[2,5,10,11]$. The transcriptional expression of two soybean IREG genes (GmIREG5 and GmIREG6) was induced by Ni (Figure 2B), combining with their different levels of tissue expression (Figure 2A), implying that GmIREG5 might be involved in Ni tolerance or accumulation above ground, while GmIREG6 might be involved in the roots. One soybean IREG gene (GmIREG3) was remarkably upregulated by $\mathrm{Al}$ in roots (Figure 2B), indicating that GmIREG3 might confer tolerance to $\mathrm{Al}$ stress. Beyond functioning in $\mathrm{Ni}, \mathrm{Co}$, and $\mathrm{Al}$ tolerance or accumulation, two IREG genes (GmIREG4 and GmIREG5) were induced by Cd in roots (Figure 2B), indicating that soybean IREG genes might have certain novel functions.

The GmIREG3 was remarkably upregulated by $\mathrm{Al}$ in roots (Figure 4), and was selected for further characterization. A BLAST search of orthologues in plants showed that GmIREG3 shared 71.5\%, 73.5\%, and 75.7\% similarity with AtIREG1, AtIREG2, and FeIREG1, respectively (Figure 3A). Subcellular localization analysis showed that GmIREG3 protein was localized in the tonoplast, as was the case for PgIREG1 (Figure 3B). Recently, FeIREG1 was functionally characterized as an Al transporter involved in $\mathrm{Al}$ tolerance [10]. These results suggested that GmIREG3 might function as $\mathrm{Al}$ transporter involved in Al tolerance. In addition, two classical abiotic stress cis-acting elements (W-box and MBS) were 
found in the promoter of GmIREG3 (Table 2). The WRKY gene family members play critical roles in certain plant processes in response to abiotic stress by directly binding to W-box (TGACC (A/T)) in the promoter of its target genes. In Arabidopsis, AtWRKY46 as a negative regulator can inhibit AtALMT1 expression, which leads to decreased malate secretion and increased $\mathrm{Al}$ accumulation in root tips [24]. In contrast, OsWRKY22 can increase the expression of OsFRDL4 by directly binding to its promoter, which enhances citrate secretion and Al tolerance in rice [25]. Although MYB transcription factors are not directly reported to be associated with $\mathrm{Al}$ resistance, Hu et al. [26] found that MdMYB73 protein bound directly to the promoters of MdALMT9, which can influence malate accumulation and vacuolar $\mathrm{pH}$. Thus, we hypothesize that GmIREG3 might play an important role in $\mathrm{Al}$ tolerance.

To further confirm GmIREG3 function in Al tolerance, transgenic Arabidopsis overexpressing GmIREG3 were generated. Consistent with this speculation, the overexpression of GmIREG3 enhanced Al tolerance in Arabidopsis (Figure 5). A recent study suggested that FeIREG1 from Fagopyrum esculentum Moench, an Al-specific tolerance IREG gene, showed similar patterns in transgenic Arabidopsis to those of GmIREG3, but also exhibited differences in the accumulation of mineral elements under $\mathrm{Al}$ tolerance with GmIREG3, such as Ca and Fe (Figure 6) [11]. In Arabidopsis, AtIREG1 is involved in the xylem loading of $\mathrm{Fe}$ and $\mathrm{Co}$, and AtIREG2 is involved in the sequestration of $\mathrm{Co}$ and $\mathrm{Ni}$ into the vacuoles $[5,10,11]$. It is important to note that neither AtIREG1 nor AtIREG2 is involved in $\mathrm{Al}$ tolerance in Arabidopsis [11]. Although GmIREG3 is the Arabidopsis orthologue of AtIREG1 and AtIREG2 (Figure 1andFigure 3A), unlike AtIREG1 and AtIREG2, our results showed that GmIREG3 is involved in the tolerance to $\mathrm{Al}$ toxicity but not to $\mathrm{Ni}$ and Co toxicity (Figure 5 and Figure S4). Moreover, GmIREG3 is expressed in the both root tip and stele (Figure $4 \mathrm{~A}$ ), and its expression was upregulated in $0-5 \mathrm{~cm}$ roots (Figure 4B), implying that GmIREG3 might participate in the sequestration of Al to the vacuoles in the root tip. These findings indicate that the functions of IREGs differ among plant species, as noted in a previous study [11]. More in-depth research on the IREG family is needed.

It is well known that certain highly tolerant species can accumulate high concentrations of $\mathrm{Al}$ in their tissues without showing symptoms of $\mathrm{Al}$ toxicity, such as buckwheat, Melastoma malabathricum, and Hydrangea plants [18]. Most plants absorb $\mathrm{Al}^{3+}$ mainly from the root tips, leading to a large accumulation of $\mathrm{Al}$ there [27-29]. Therefore, there must be an internal detoxification mechanism in the root tips and other tissues. Vacuoles play an important role in the storage of toxic substances in plant cells. Metal sequestration in the vacuole has been well established to detoxify toxic metal internally, which is a relatively mature toxic metal resistance mechanism in higher plants [30-34]. In previous studies, two half-size ABC transporters, AtALS1 and OsALS1, were reported to be involved in $\mathrm{Al}$ tolerance by sequestration of $\mathrm{Al}$ to the vacuoles in the root cells $[8,9]$. In the present study, like FeIREG1, AtALS1, and OsALS1, GmIREG3 was shown to be localized in the tonoplast (Figure 3B). Furthermore, transgenic Arabidopsis overexpressing GmIREG3 showed an increased tolerance to elevated concentrations of $\mathrm{Al}$ (Figure 5). The most likely cause of this phenotype is that GmIREG3 is involved in $\mathrm{Al}$ tolerance by sequestrating $\mathrm{Al}$ into the vacuoles of roots.

Soybean (Glycine max L.) is one of the most important sources of protein, oil, and micronutrients, and is particularly sensitive to $\mathrm{Al}$ toxicity. To date, some Al-tolerant genes have been reported in soybean, but information on the IREG family is limited. This study systematically characterized the GmIREGs and their metal-induced expression patterns in soybean. Moreover, we established that GmIREG3 plays a role similar to that of FeIREG1 in contributing to Al tolerance. These results supply basic and important information for understanding the putative functions of IREG genes in soybean.

\section{Materials and Methods}

\subsection{Identification and Bioinformatics Analyses of IREG Genes in Soybean}

To identify IREG homologues in soybean, the nucleic acid sequences of reported IREGs in Arabidopsis (AtIREG1, AtIREG2, and AtIREG3), buckwheat (FeIREG1), and Psychotria gabriellae (PgIREG1) were used as query sequences to BLAST from soybean genomes in Phytozome v12 (available online: 
https://phytozome.jgi.doe.gov/pz/portal.html\#!search?show=BLAST\&method=Org_Gmax, accessed on 21 October 2016). Six proteins with IREG domains were identified through filtering with the presence of conserved IREG domain (Pfam: PF06963) using Pfam (available online: http://pfam.xfam. org/, accessed on 21 October 2016) and the Simple Modular Architecture Research Tool (SMART, available online: http://smart.embl-heidelberg.de/smart/batch.pl, accessed on 21 October 2016) [35,36]. GmIREG1 (Glyma.01G128300), GmIREG2 (Glyma.01G128400), GmIREG3 (Glyma.03G042400), GmIREG4 (Glyma.03G042500), GmIREG5 (Glyma.10G146600), and GmIREG6 (Glyma.20G096400) were named accordingly. The chromosomal locations of GmIREG genes were illustrated by MapChart [37]. The deduced protein sequences of all six GmIREGs and reported IREGs were used for multiple sequence alignments through ClustalX and GeneDoc software. The phylogenetic tree with other IREG genes was analyzed using the neighbor-joining method in the MEGA7.0 program with 1000 bootstrap replicates. PlantCARE (available online: http://bioinformatics.psb.ugent.be/webtools/plantcare/html/, accessed on 28 December 2017) was used for cis-element analysis in the 1958 bp region upstream of the start codon for GmIREG3.

\subsection{Plant Materials and Stress Treatments}

Soybean cv. HX3 (Al-tolerant genotype) was employed in this study. Soybean seeds were surface sterilized in $75 \%$ alcohol followed by germination for three days in sterile vermiculite. Seedlings of similar size were transplanted into the corresponding nutrient solution for gene cloning and transcriptional expression experiments. To investigate possible responses of GmIREGs to Fe deficiency, uniform seedlings were exposed to normal conditions (half-strength nutrient solution, $\mathrm{pH}$ 5.6) or low-iron conditions (half-strength nutrient solution without Fe-Na-EDTA, pH 5.6) for 14 days, during which time nutrient deficiency was observed [38]. For other treatments, uniform seedlings were exposed to a nutrient solution as previously described [39]; the nutrient solution contained $200 \mathrm{mM}$ $\mathrm{CaSO}_{4}, 200 \mathrm{mM} \mathrm{CaCl}_{2}, 100 \mathrm{mM} \mathrm{MgSO}_{4}, 400 \mathrm{mM} \mathrm{KNO}_{3}, 300 \mathrm{mM} \mathrm{NH}_{4} \mathrm{NO}_{3}, 5 \mathrm{mM} \mathrm{NaH}_{2} \mathrm{PO}_{4}, 3 \mathrm{mM}$ $\mathrm{H}_{3} \mathrm{BO}_{3}, 0.5 \mathrm{mM} \mathrm{MnCl}_{2}, 0.4 \mathrm{mM} \mathrm{ZnSO}_{4}, 0.2 \mathrm{mM} \mathrm{CuSO}_{4}, 10 \mathrm{mM}$ Fe-EDTA, and $1 \mathrm{mM}\left(\mathrm{NH}_{4}\right)_{6} \mathrm{Mo}_{7} \mathrm{O}_{24}$. The solution was adjusted to $\mathrm{pH} 4.5$ with $\mathrm{HCl}$ and renewed daily. After $2 \mathrm{~d}$ of culture, the uniform seedlings were subjected to the following treatments. To elucidate the probable functions of GmIREGs in response to metal toxicity stresses, seedlings were treated with excess $\mathrm{Fe}(1000 \mu \mathrm{M}$ Fe-EDTA), Ni $\left(30 \mu \mathrm{M} \mathrm{NiCl} 2 \cdot 6 \mathrm{H}_{2} \mathrm{O}\right), \mathrm{Cd}\left(30 \mu \mathrm{M} \mathrm{CdCl}_{2}\right), \mathrm{Co}\left(30 \mu \mathrm{M} \mathrm{CoCl}_{2}\right)$, and $\mathrm{Al}\left(30 \mu \mathrm{M} \mathrm{AlCl} \cdot 6 \mathrm{H}_{2} \mathrm{O}\right)$ for $12 \mathrm{~h}$. For the time-course experiment, seedlings were exposed to $30 \mu \mathrm{M} \mathrm{AlCl}_{3}$ for $0,1,2,4,8,12$, or $24 \mathrm{~h}$. A dose-dependent experiment was performed by exposing the seedlings to different $\mathrm{Al}$ concentrations $(0,7.5,15,30$, and $50 \mu \mathrm{M})$. Samples for spatial expression were taken from different root segments $(0-1$, $1-2$, and $2-5 \mathrm{~cm}$ from the apex) of the seedlings. Each treatment had four biological replicates.

\subsection{Analysis of Expression}

Total RNA was isolated from the samples using the Plant Total RNA Purification Kit (TR02-150, GeneMarkbio, Taiwan). One microgram of total RNA was synthesized into first-strand cDNA using the PrimeScript ${ }^{\mathrm{TM}}$ RT reagent Kit with a gDNA Eraser kit (RR047, TAKARA, Shiga, Japan). Quantitative real-time PCR (qRT-PCR) was performed to determine the transcriptional expression level of GmIREG genes using the TB Green ${ }^{\text {TM }}$ Premix Ex Taq ${ }^{\text {TM }}$ II (RR820, TAKARA, Shiga, Japan) in a CFX96 Real-Time System (Bio-Rad, Hercules, CA, USA) with GmActin6 (GenBank: AK285830.1) or AtActin2 (At3g18780) as an internal control. The primers used in the qRT-PCR reactions are listed in Supplemental Table S1. For all experiments, qRT-PCRs were performed in triplicate on three different RNA samples isolated independently from each tested condition. The relative expression level of the genes was computed by the $2-\Delta \Delta \mathrm{Ct}$ method [40]. The FPKM of six GmIREGs in nodules, root, root hairs, stem, shoot apical meristem, leaves, flower, pod, and seed were downloaded from phytozome v12 (available online: https://phytozome.jgi.doe.gov/pz/portal.html\#!search?show=BLAST\&method=Org_Gmax, accessed on 21 October 2016). 


\subsection{Subcellular Localization of GmIREG3}

A 1958 bp promoter region of GmIREG3 was obtained from the genomic DNA of HX3 using Clone-GmIREG3F/R primers. The amplified fragments were subsequently cloned into the pLB vector (VT205, TIANGEN) for sequence confirmation. To construct the GmIREG3-GFP fusion-protein-expressing constructs, GmIREG3 cDNA was amplified from the cDNA using specific primers (Supplemental Table S1) and inserted into the Nco I and Spe I sites of the pCambia 1302 vector using the ClonExpress ${ }^{\circledR}$ II One Step Cloning Kit (C112, Vazyme, Nanjing, China). Subcellular localization was investigated by overexpressing 35S:GmIREG3-GFP transiently in tobacco (Nicotiana tabacum) leaves by Agrobacterium-mediated transformation [41]. The GFP fluorescence was observed using confocal scanning microscopy (LSM780, Zeiss, Jena, Germany).

\subsection{Functional Characterization of GmIREG3 in Transgenic Arabidopsis}

To construct the GmIREG3 overexpression (OX) vectors, the open reading frame of GmIREG3, which was prepared for subcellular localization investigation as described above, was ligated between CaMV 35S and the NOS terminator of the pTF101.1-GFP vector using the ClonExpress ${ }^{\circledR}$ II One Step Cloning Kit (Vazyme, Nanjing, China). The resulting GmIREG3 overexpression construct was transformed into Agrobacterium strain GV3101, which was then used for Arabidopsis transformation according to the Agrobacterium tumefaciens-mediated floral dip method [21,22]. The expression of GmIREG3 in transgenic plants was quantified by qRT-PCR. Two representative transgenic homozygous $\mathrm{T} 3$ lines were used for an $\mathrm{Al}$ sensitivity assays by measuring relative root elongation according to Yokosho et al. [11]. After germination in MS medium, five-day-old seedlings were transferred to solid agar medium supplied with $1 \mathrm{mM} \mathrm{CaCl}$ and $1 \%$ sucrose containing different concentrations of $\mathrm{AlCl}_{3}$ $\left(0,25,50\right.$ or $100 \mu \mathrm{M}$; pH 4.5), $\mathrm{NiCl}_{2}(0,5$ or $10 \mu \mathrm{M} ; \mathrm{pH} 5.0)$, and $\mathrm{CoCl}_{2}(0,5$ or $10 \mu \mathrm{M} ; \mathrm{pH}$ 5.0). Their root lengths were measured before and after $3 \mathrm{~d}$ of different treatments. The relative root elongation (RRE) was computed as (root elongation with different treatments/root elongation without treatments) $\times 100$. The root samples were used for the determination of $\mathrm{Al}$ contents. For the determination of the $\mathrm{K}, \mathrm{Ca}$, $\mathrm{Mg}$, and Fe concentration in the transgenic roots, one-week-old plants were exposed to 1/30 Hoagland solution without $\mathrm{NH}_{4} \mathrm{H}_{2} \mathrm{PO}_{4}$, but with $1 \mathrm{mM} \mathrm{CaCl}_{2}$ in the absence or presence of $10 \mu \mathrm{M} \mathrm{AlCl}_{3}$ at $\mathrm{pH}$ 4.5. After one week, the roots were harvested separately and then used for the determination of $\mathrm{K}, \mathrm{Ca}$, $\mathrm{Mg}$, and Fe contents by ICP-AES.

\subsection{Statistical Analysis}

All data were analyzed using GraphPad Prism ${ }^{\circledR} 5$ (Version 5.01, GraphPad Software, Inc., USA) for calculating mean and standard deviation. At least three biological replicates were included in the data, and all data were analyzed using ANOVA or Duncan's test for the determination of the significant differences with SPSS 21 (IBM Corp, 2012). The Heatmap_V2.16 (available online: http://www.lc-bio.cn/overview/8?tools=Heatmap_V2.16, accessed on 10 August 2019) was used to construct the heat map to analyze the tissue-specific expression and the metal-induced expression of GmIREGs.

Supplementary Materials: Supplementary materials can be found at http://www.mdpi.com/1422-0067/21/2/497/s1.

Author Contributions: Conceptualization, Z.C. and H.N.; Data curation, Q.M.; Formal analysis, P.X.; Funding acquisition, H.N.; Methodology, Z.C., R.L. and Y.C.; Project administration, Z.C.; Validation, P.X.; Writing-original draft, Z.C.; Writing-review \& editing, Z.C., P.X., R.L., T.L., Q.M. and H.N. All authors have read and agreed to the published version of the manuscript.

Funding: This research was funded by the Projects of Science and Technology of Guangzhou (201804020015); the China Agricultural Research System (CARS-04-PS09) and the Research Project of the State Key Laboratory for Conservation and Utilization of Subtropical Agro-bioresources (SKLCUSA-b201804).

Acknowledgments: We thank the members of the Guangdong Subcenter of the National Center for Soybean Improvement for their daily help. 
Conflicts of Interest: The authors declare no conflict of interest. The funders had no role in the design of the study; in the collection, analyses, or interpretation of data; in the writing of the manuscript, or in the decision to publish the results.

$\begin{array}{ll}\text { Abbreviations } \\ \text { IREG } & \text { IRON REGULATED } \\ \text { FNP } & \text { Ferroportin } \\ \text { GFP } & \text { Green fluorescence protein } \\ \text { qRT-PCR } & \text { Real-time quantitative polymerase chain reaction } \\ \text { ORF } & \text { Open reading frame } \\ \text { WT } & \text { Wild type } \\ \text { ICP-AES } & \text { Inductively coupled plasma-atomic emission spectrometry } \\ \text { FPKM } & \text { Fragments Per Kilobase per Million }\end{array}$

\section{References}

1. Hall, J.; Williams, L.E. Transition metal transporters in plants. J. Exp. Bot. 2003, 54, 2601-2613. [CrossRef]

2. Merlot, S.; Hannibal, L.; Martins, S.; Martinelli, L.; Amir, H.; Lebrun, M.; Thomine, S. The metal transporter PgIREG1 from the hyperaccumulator Psychotria gabriellae is a candidate gene for nickel tolerance and accumulation. J. Exp. Bot. 2014, 65, 1551-1564. [CrossRef]

3. Sasaki, A.; Yamaji, N.; Ma, J.F. Transporters involved in mineral nutrient uptake in rice. J. Exp. Bot. 2016, 67, 3645-3653. [CrossRef]

4. Wu, D.; Yamaji, N.; Yamane, M.; Kashino-Fujii, M.; Sato, K.; Ma, J.F. The HvNramp5 transporter mediates uptake of cadmium and manganese, but not iron. Plant Physiol. 2016, 172, 1899-1910. [CrossRef]

5. Schaaf, G.; Honsbein, A.; Meda, A.R.; Kirchner, S.; Wipf, D.; von Wirén, N. AtIREG2 encodes a tonoplast transport protein involved in iron-dependent nickel detoxification in Arabidopsis thaliana roots. J. Biol. Chem. 2006, 281, 25532-25540. [CrossRef]

6. Cebeci, O.; Kokturk, B.; Ergen, N.; Ozturk, L.; Cakmak, I.; Budak, H. Differential expression of wheat transcriptomes in response to varying cadmium concentrations. Biol. Plantarum 2008, 52, 703. [CrossRef]

7. Morales-Cedillo, F.; Gonzalez-Solis, A.; Gutierrez-Angoa, L.; Cano-Ramírez, D.L.; Gavilanes-Ruiz, M. Plant lipid environment and membrane enzymes: The case of the plasma membrane $\mathrm{H}^{+}$-ATPase. Plant Cell Rep. 2015, 34, 617-629. [CrossRef]

8. Huang, C.F.; Yamaji, N.; Chen, Z.; Ma, J.F. A tonoplast-localized half-size ABC transporter is required for internal detoxification of aluminum in rice. Plant J. 2012, 69, 857-867. [CrossRef]

9. Larsen, P.B.; Cancel, J.; Rounds, M.; Ochoa, V. Arabidopsis ALS1 encodes a root tip and stele localized half type ABC transporter required for root growth in an aluminum toxic environment. Planta 2007, 225, 1447. [CrossRef]

10. Morrissey, J.; Baxter, I.R.; Lee, J.; Li, L.; Lahner, B.; Grotz, N.; Kaplan, J.; Salt, D.E.; Guerinot, M.L. The ferroportin metal efflux proteins function in iron and cobalt homeostasis in Arabidopsis. Plant Cell 2009, 21, 3326-3338. [CrossRef]

11. Yokosho, K.; Yamaji, N.; Mitani-Ueno, N.; Shen, R.F.; Ma, J.F. An aluminum-inducible IREG gene is required for internal detoxification of aluminum in buckwheat. Plant Cell Physiol. 2016, 57, 1169-1178. [CrossRef]

12. Conte, S.; Stevenson, D.; Furner, I.; Lloyd, A. Multiple antibiotic resistance in Arabidopsis is conferred by mutations in a chloroplast-localized transport protein. Plant Physiol. 2009, 151, 559-573. [CrossRef]

13. Conte, S.S.; Lloyd, A.M. The MAR1 transporter is an opportunistic entry point for antibiotics. Plant Signal. Behav. 2010, 5, 49-52. [CrossRef]

14. Kochian, L.V.; Pineros, M.A.; Hoekenga, O.A. The physiology, genetics and molecular biology of plant aluminum resistance and toxicity. In Root Physiology: From Gene to Function; Springer: Dordrecht, The Netherlands, 2005; pp. 175-195.

15. Zhou, Y.; Yang, Z.; Gong, L.; Liu, R.; Sun, H.; You, J. Molecular characterization of GmSTOP1 homologs in soybean under Al and proton stress. Plant Soil 2018, 427, 213-230. [CrossRef]

16. Kochian, L.V.; Piñeros, M.A.; Liu, J.; Magalhaes, J.V. Plant adaptation to acid soils: The molecular basis for crop aluminum resistance. Annu. Rev. Plant Biol. 2015, 66, 571-598. [CrossRef] 
17. Ma, J.F. Syndrome of aluminum toxicity and diversity of aluminum resistance in higher plants. Int. Rev. Cytol. 2007, 264, 225-252.

18. Ma, J.F.; Ryan, P.R.; Delhaize, E. Aluminium tolerance in plants and the complexing role of organic acids. Trends Plant Sci. 2001, 6, 273-278. [CrossRef]

19. Hoekenga, O.A.; Maron, L.G.; Piñeros, M.A.; Cançado, G.M.; Shaff, J.; Kobayashi, Y.; Ryan, P.R.; Dong, B.; Delhaize, E.; Sasaki, T. AtALMT1, which encodes a malate transporter, is identified as one of several genes critical for aluminum tolerance in Arabidopsis. Proc. Natl. Acad. Sci. USA 2006, 103, 9738-9743. [CrossRef]

20. Yokosho, K.; Ma, J.F. Transcriptional regulation of Al tolerance in plants. In Aluminum Stress Adaptation in Plants; Springer: Cham, Switzerland, 2015; pp. 37-46.

21. Zhang, X.; Henriques, R.; Lin, S.-S.; Niu, Q.-W.; Chua, N.-H. Agrobacterium-mediated transformation of Arabidopsis thaliana using the floral dip method. Nat. Protoc. 2006, 1, 641. [CrossRef]

22. Clough, S.J.; Bent, A.F. Floral dip: A simplified method for Agrobacterium-mediated transformation of Arabidopsis thaliana. Plant J. 1998, 16, 735-743. [CrossRef]

23. Muckenthaler, M.U.; Galy, B.; Hentze, M.W. Systemic iron homeostasis and the iron-responsive element/iron-regulatory protein (IRE/IRP) regulatory network. Annu. Rev. Nutr. 2008, 28, 197-213. [CrossRef] [PubMed]

24. Ding, Z.J.; Yan, J.Y.; Xu, X.Y.; Li, G.X.; Zheng, S.J. WRKY 46 functions as a transcriptional repressor of ALMT1, regulating aluminum-induced malate secretion in Arabidopsis. Plant J. 2013, 76, 825-835. [CrossRef] [PubMed]

25. Li, G.Z.; Wang, Z.Q.; Yokosho, K.; Ding, B.; Fan, W.; Gong, Q.Q.; Li, G.X.; Wu, Y.R.; Yang, J.L.; Ma, J.F. Transcription factor WRKY22 promotes aluminum tolerance via activation of OsFRDL4 expression and enhancement of citrate secretion in rice (Oryza sativa). New Phytol. 2018, 219, 149-162. [CrossRef] [PubMed]

26. Hu, D.G.; Li, Y.Y.; Zhang, Q.Y.; Li, M.; Sun, C.H.; Yu, J.Q.; Hao, Y.J. The R2R3-MYB transcription factor Md MYB73 is involved in malate accumulation and vacuolar acidification in apple. Plant J. 2017, 91, 443-454. [CrossRef]

27. Lazof, D.B.; Goldsmith, J.G.; Rufty, T.W.; Linton, R.W. Rapid uptake of aluminum into cells of intact soybean root tips (a microanalytical study using secondary ion mass spectrometry). Plant Physiol. 1994, 106, 1107-1114. [CrossRef]

28. Matsumoto, H.; Hirasawa, E.; Torikai, H.; Takahashi, E. Localization of absorbed aluminium in pea root and its binding to nucleic acids. Plant Cell Physiol. 1976, 17, 127-137. [CrossRef]

29. Zheng, S.J.; Ma, J.F.; Matsumoto, H. High aluminum resistance in buckwheat: I. Al-induced specific secretion of oxalic acid from root tips. Plant Physiol. 1998, 117, 745-751. [CrossRef]

30. Jia-Wen, W.; Yu, S.; Yong-Xing, Z.; Yi-Chao, W.; Hai-Jun, G. Mechanisms of enhanced heavy metal tolerance in plants by silicon: A review. Pedosphere 2013, 23, 815-825.

31. Kochian, L.V.; Hoekenga, O.A.; Pineros, M.A. How do crop plants tolerate acid soils? Mechanisms of aluminum tolerance and phosphorous efficiency. Annu. Rev. Plant Biol. 2004, 55, 459-493. [CrossRef]

32. Ma, J.F.; Hiradate, S.; Matsumoto, H. High aluminum resistance in buckwheat: II. Oxalic acid detoxifies aluminum internally. Plant Physiol. 1998, 117, 753-759. [CrossRef]

33. Verkleij, J.; Lolkema, P.; De Neeling, A.; Harmens, H. Heavy metal resistance in higher plants: Biochemical and genetic aspects. In Ecological Responses to Environmental Stresses; Springer: Dordrecht, The Netherlands, 1991; pp. 8-21.

34. Watanabe, T.; Osaki, M.; Yoshihara, T.; Tadano, T. Distribution and chemical speciation of aluminum in the Al accumulator plant, Melastoma malabathricum L. Plant Soil 1998, 201, 165-173. [CrossRef]

35. Finn, R.D.; Bateman, A.; Clements, J.; Coggill, P.; Eberhardt, R.Y.; Eddy, S.R.; Heger, A.; Hetherington, K.; Holm, L.; Mistry, J. Pfam: The protein families database. Nucleic Acids Res. 2013, 42, D222-D230. [CrossRef]

36. Letunic, I.; Doerks, T.; Bork, P. SMART: Recent updates, new developments and status in 2015. Nucleic Acids Res. 2014, 43, D257-D260. [CrossRef]

37. Voorrips, R. MapChart: Software for the graphical presentation of linkage maps and QTLs. J. Hered. 2002, 93, 77-78. [CrossRef]

38. Qin, L.; Han, P.; Chen, L.; Walk, T.C.; Li, Y.; Hu, X.; Xie, L.; Liao, H.; Liao, X. Genome-wide identification and expression analysis of NRAMP family genes in soybean (Glycine max L.). Front. Plant Sci. 2017, 8, 1436. [CrossRef] 
39. Lou, H.Q.; Gong, Y.L.; Fan, W.; Xu, J.M.; Liu, Y.; Cao, M.J.; Wang, M.-H.; Yang, J.L.; Zheng, S.J. A formate dehydrogenase confers tolerance to aluminum and low pH. Plant Physiol. 2016, 171, 294-305. [CrossRef]

40. Livak, K.J.; Schmittgen, T.D. Analysis of relative gene expression data using real-time quantitative PCR and the $2^{-\Delta \Delta C T}$ method. Methods 2001, 25, 402-408. [CrossRef]

41. Sparkes, I.A.; Runions, J.; Kearns, A.; Hawes, C. Rapid, transient expression of fluorescent fusion proteins in tobacco plants and generation of stably transformed plants. Nat. Protoc. 2006, 1, 2019. [CrossRef]

(C) 2020 by the authors. Licensee MDPI, Basel, Switzerland. This article is an open access article distributed under the terms and conditions of the Creative Commons Attribution (CC BY) license (http://creativecommons.org/licenses/by/4.0/). 